choice and duration of antimicrobial therapy, and an understanding of the potential complications and their respective treatment. Knowledge of the existence of this clinical entity is the first step to early recognition and appropriate management.

1 Periappuram M, Taylor MRH, Keane CT. Rapid detection of meningococci from petechiae in adults in acute meningococcal infection. F Infect 1995; 31: 201-3.

2 Watanakunakorn C, Tan JS, Phair JP. Some salient features of Staphylococcus aureus endocarditis. Am F Med 1973; 54: 473-81.

3 Watanakunakorn C. Staphylococcus aureus endocarditis at a community teaching hospital, 1980 to 1991 . Arch Intern Med 1994; 154: 2330-5.

\section{Final diagnosis}

\section{Staphylococcus aureus endocarditis}

Keywords: Staphylococcus aureus, endocarditis, meningococcal septicaemia, differential diagnosis

4 Perkins MD, Mirret S, Reller LB. Rapid bacterial antigen detection is not clinically useful. f Clin Microbiol 1995; 33: $1486-91$

5 Murray HW, Tuazon CU, Sheagren JN. Staphylococcal septicaemia and disseminated intravascular coagulation. Staphylococcus aureus endocarditis mimicking meningococcaemia. Arch Intern Med 1977; 137: 844-7.

\title{
A retrocardiac shadow in an immunocompromised patient
}

\author{
FU Huwez, MJ Stewart, AR McPhaden, IS Stewart, SK Naik, D Richens, DJ Wheatley
}

A 53-year-old male ex-smoker underwent orthotopic heart transplantation for severe heart failure following a massive anterior myocardial infarction. Immunosuppression was induced with equine antithymocyte globulin and maintained on cyclosporin A, azathioprine and prednisolone. Virological screen before transplantation revealed positive serology for cytomegalovirus but he was negative for Epstein-Barr virus (EBV). The patient remained well until about two and half years post-transplant when he presented with features of left ventricular failure following symptoms of a chest infection. The latter was treated with two courses of antibiotics in the community prior to his presentation. On examination he was haemodynamically stable and

The Royal Infirmary, Glasgow G31 2ER, UK

Department of Cardiac Surgery

FU Huwez

SK Naik

D Richens

DJ Wheatley

Department of

Medical Cardiology

MJ Stewart

Department of

Pathology

AR McPhaden

Department of

Radiology

IS Stewart

Correspondence to

Dr FU Huwez,

Department of Medicine,

Edgeware General

Hospital, Edgeware,

Middlesex HA8 OAD, UK

Accepted 7 March 1996 afebrile. Electrocardiogram revealed evidence of an acute inferior myocardial infarction which was complicated by heart block, necessitating insertion of a permanent pacemaker. Chest X-ray showed elevation of the left hemi-diaphragm, a small left pleural effusion and a rounded opacity behind the left cardiac border. A contrast computed tomography (CT) scan of the chest was carried out (figure 1).

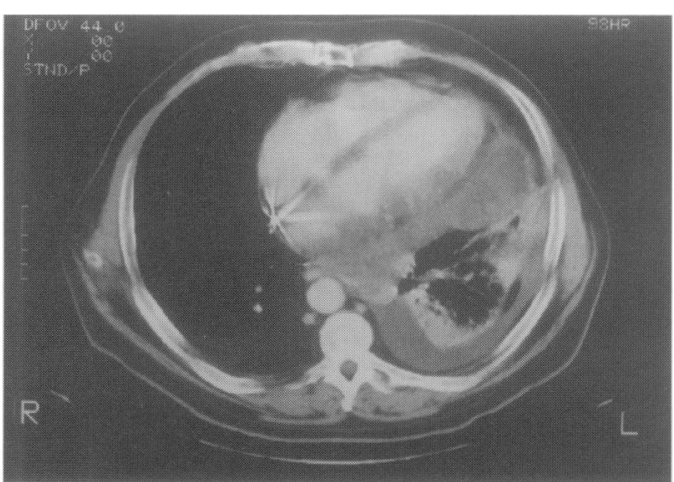

Figure 1 CT scan of the chest

\section{Questions}

1 What are the findings on the CT scan? 2 What further investigations are required ? 3 What is the differential diagnosis? 


\section{Answers}

QUESTION 1

The contrast-enhanced CT scan shows a small left basal effusion with collapse/consolidation of the left lower lobe. There is a normal right ventricular chamber and interventricular septum but there is abnormally thick left ventricular wall and a large soft tissue mass intimately related to the left heart border.

\section{QUESTION 2}

The following investigations were necessary to reach a definitive diagnosis:

- CT guided aspiration of the left pulmonary lesion

- bronchoscopy and bronchoalveolar lavage

- thoracotomy and biopsy since the two preceding investigations were nondiagnostic.

\section{QUESTION 3}

The presence of a retrocardiac mass with localised airway obstruction usually indicates an expanding neoplastic lesion. However, in the immunocompromised patient, an atypical infective process has to be excluded (box). Both the CT-guided aspiration of the left pulmonary lesion and the bronchoscopy with bronchoalveolar lavage were nondiagnostic. Left thoracotomy revealed a hard, greyish-white mass between the pericardium and the left lung, infiltrating both structures. Light microscopy and immunocytochemistry of this mass revealed an EBV-positive large B cell lymphoma. Cyclosporin A was withdrawn and long term oral acyclovir started. Whole body scan did not reveal involvement of other organs. The tumour continued to enlarge and the patient died six months after presentation despite effective treatment of three episodes of allograft rejection. At post mortem there was extensive mediastinal involvement by the lymphoma which had largely obliterated the pericardial cavity and was infiltrating the lateral, posterior and inferior walls of the left ventricle (figure 2). Infiltration of the medial aspect of the lower lobe of the left lung was also present. A 15-mm diameter area of scarring was seen in the inferior aspect of the left ventricular wall consistent with old inferior myocardial infarction.

\section{Discussion}

Development of malignancies is promoted by immunosuppressive therapy after allograft

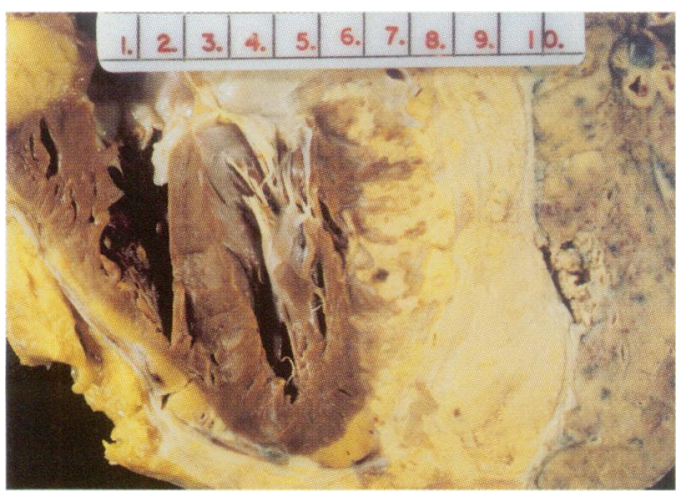

Differential diagnosis of a retrocardiac mass with pulmonary involvement in an

immunocompromised patient

- bronchogenic or oesophageal carcinoma

- metastatic from outwith the mediastinum

- EBV-related B cell lymphoma

- non-EBV related mediastinal lymphoma

- pleural or pericardial mesothelioma

- malignant primary cardiac tumours including angiosarcoma, fibrosarcoma, and rhabdomyosarcoma

- Kaposi's sarcoma with mediastinal involvement

- primary malignant neurogenic tumours of the posterior mediastinum

- haemopoietic tumours with mediastinal involvement

- atypical infections involving lung and pericardium including mycobacterium, nocardiosis and fungal infections. These must be excluded as they are treatable

transplantation. Transplant recipients have a $6 \%$ risk of developing a malignant tumour which represents an age-controlled frequency 100 times greater than that of the general population. ${ }^{1}$ The use of cyclosporin $A$ in transplant patients has been particularly associated with an increase in Kaposi's sarcoma and B cell lymphomas. ${ }^{2}$ These post-transplant lymphomas which occur in $12 \%$ of all solid organ transplant recipients, ${ }^{3}$ almost universally contain EBV. ${ }^{4}$ In immunocompromised posttransplant patients, the normal $\mathrm{T}$-cell inhibition of proliferating EBV-infected B cells is ineffective, thereby promoting the development of an EBV-positive B cell tumour. The incidence of this tumour has declined with reduction of cyclosporin A dosage and reduced usage of antithymocyte globulin. ${ }^{5}$ Acyclovir accompanied by reduced immunosuppression may induce remission of EBV-related $B$ cell lymphomas in transplant recipients without recourse to other forms of therapy. ${ }^{6}$

\section{Final diagnosis}

Post-transplant EBV-related large B cell lymphoma.

Keywords: retrocardiac mass, lymphoma, heart transplantation, immunosuppression, Epstein-Barr virus

1 Penn I. Malignancies associated with immunosuppressive or cytotoxic therapy. Surgery 1978; 83: 492-502.

2 Penn I, Brunson ME. Cancers after cyclosporin therapy. Transplant Proc 1987; 20: 885-7.

3 Swerdlow SH. Post-transplant lymphoproliferative disorders : a morphologic, phenotypic and genotypic spectrum of disease. Histopathology 1992; 20: 373-85.

4 Hanto DW, Sakamato K, Puitilo DT, Simmons RL, Najarian JS. The Epstein-Barr virus in the pathogenesis of post-transplant lymphoproliferative disorders. Surgery 1981; 90: $204-13$.

5 Starzl TE, Nalesnik MA, Porter KA, et al. Reversibility of lymphomas and lymphoproliferative lesions developing under cyclosporin-steroid therapy. Lancet 1984; I: $583-7$.

6 Hanto DW, Gajl-Peczalska KJ, Balfour HH, et al. Acyclovir therapy of Epstein-Barr virus induced post-transplant tymphoproliferative disease. Transplant Proc 1985; 17: 89-
92. 